\title{
$\mathrm{PH} \mathbf{8 8}_{\text {perspectivas }}$
}

a debate La eficiencia energética y la edificación histórica | coordinan Mónica López Sánchez, Ana Yáñez Vega

\section{Cómo mejorar la eficiencia energética de los sitios y construcciones históricas conservando su carácter, valores e integridad histórica}

Andrew Richards | Cornwall Council (Traducción: M. ${ }^{a}$ Victoria Madrid Díaz)

URL de la contribución <www.iaph.es/revistaph/index.php/revistaph/article/view/3663>

Los edificios históricos son en esencia sostenibles. La mayoría ha sobrevivido porque son robustos, resistentes y adaptables. Aportan un toque distintivo, significado y calidad a los lugares en los que vivimos, al tiempo que proporcionan una sensación de continuidad e identidad propia.

Los edificios tradicionales son complejos y su relación con las nuevas construcciones funciona de formas diversas. Mejorar el rendimiento térmico requiere un acercamiento al "edificio en su conjunto", teniendo en cuenta su ubicación, la construcción, sus condiciones, la eficiencia de los servicios que se prestan en él, el valor patrimonial, su significación y el comportamiento de sus habitantes.
Cuando una construcción tradicional funciona según lo previsto, hay un equilibrio entre la ventilación, el calor y la humedad. A veces, llevar a cabo modificaciones bienintencionadas para mejorar la eficiencia energética puede alterar este equilibrio y dañar la estructura y salud del edificio así como el bienestar de sus habitantes.

En el Reino Unido, existen investigaciones de calidad y guías para edificaciones tradicionales pero no han tenido influencia en la política del Gobierno Británico o en los criterios para otorgar subvenciones para la rehabilitación de los edificios más antiguos. Se necesita una mayor participación de los profesionales del patrimonio en la

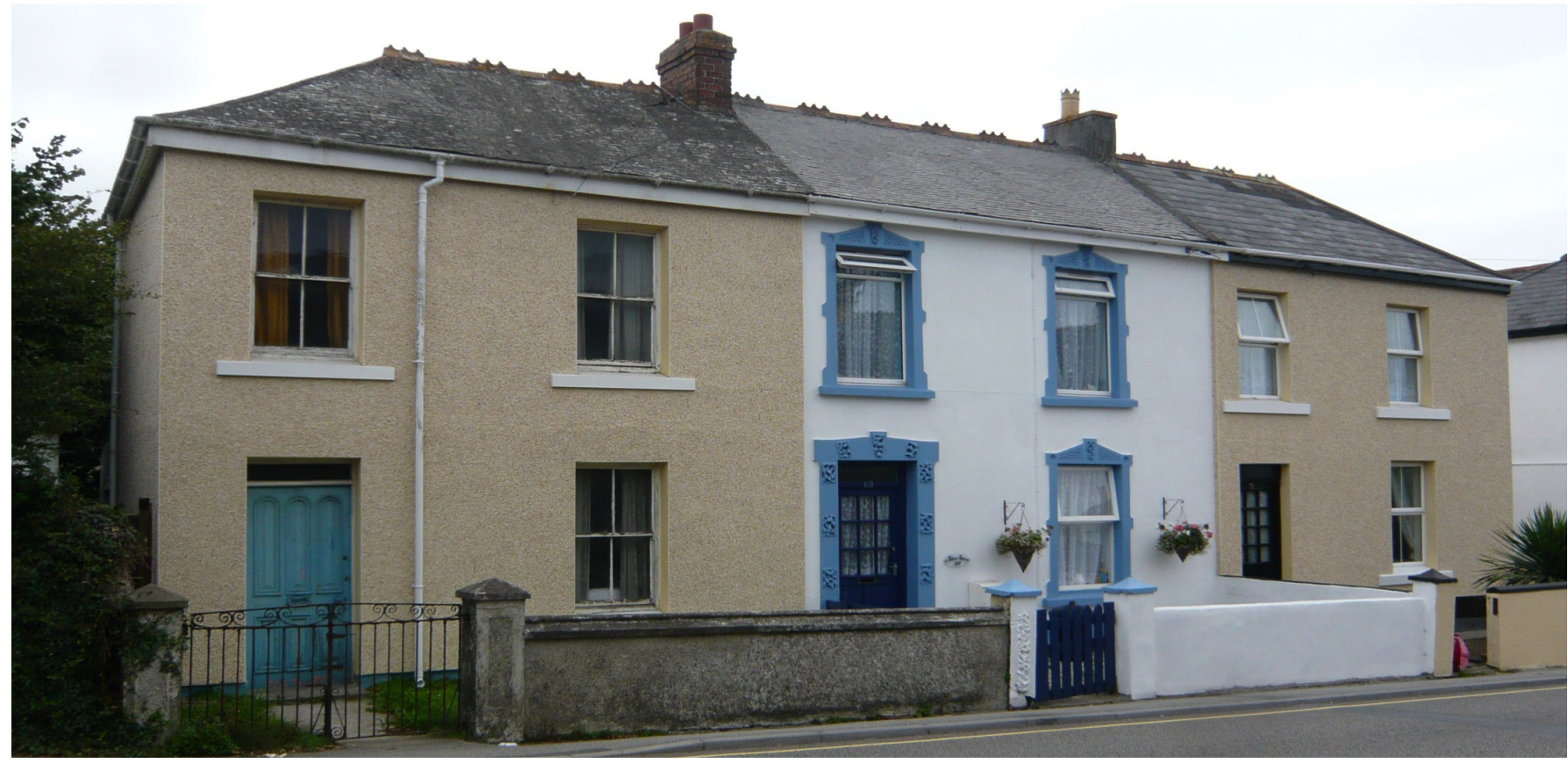

El aislamiento exterior de terrazas en Camborne está provocando la pérdida de material original y el carácter arquitectónico de las construcciones, especialmente en ventanas y puertas. Forma parte de un programa financiado por el Gobierno para la mejora de los edificios más antiguos | foto Andrew Richards 
_a debate La eficiencia energética y la edificación histórica | coordinan Mónica López Sánchez, Ana Yáñez Vega

política y en la administración para permitir un replanteamiento radical en la política de rehabilitaciones.

En este país la modificación y ampliación de edificios históricos requieren presentar a las autoridades locales una planificación y una solicitud de autorización para actuar sobre edificios catalogados. Sin embargo, los detalles que tienen mayor probabilidad de afectar al carácter del edificio histórico suelen incluirse en las solicitudes de "control de edificaciones" que se envían en una fase posterior, una vez obtenidos los permisos.

Los recortes en personal especializado en conservación en la administración local y en los órganos consultivos de patrimonio han llevado a que muchas de estas solicitudes se respondan con escaso asesoramiento especializado. Los arquitectos que presentan los proyectos e inspeccionan el trabajo y a los constructores locales tampoco tienen siempre experiencia en arquitectura tradicional.

Con recursos tan limitados, resulta esencial contar con una buena orientación a través de la web para informar a las solicitudes presentadas. Establecer un calendario de formación sobre el tema y organizar talleres y seminarios web facilitarían la adopción de una postura conjunta al reunir a los profesionales locales, los constructores, los estudiantes universitarios y los concejales.

Desde hace tiempo, existe una gran carencia de especialistas e instaladores con conocimientos sobre arquitectura tradicional. Las técnicas empleadas en la construcción tradicional raras veces se enseñan en las escuelas universitarias locales y los contratistas con frecuencia prefieren reemplazar antes que rehabilitar la estructura original de la edificación, lo que afecta al carácter del edificio.

Los edificios históricos son complejos y se beneficiarían si hubiera una mayor investigación y supervisión. Con frecuencia tienen muros sólidos con una buena masa térmica y capacidad de absorción, almacenamiento y liberación de calor a lo largo del tiempo. Esto puede evi- tar el sobrecalentamiento en verano y reducir la necesidad de un medio mecánico de refrigeración.

Actualmente, existen nuevos productos transpirables y sostenibles que podrían utilizarse en las rehabilitaciones y ampliaciones de edificios tradicionales. Muchos de estos productos tienen sólo una certificación europea y son desconocidos para los inspectores de control de la edificación y para los constructores locales.

La arquitectura tradicional generalmente se apoya en la permeabilidad de su estructura para resistir la penetración y la retención de la humedad. Muchos se adaptan mediante un sistema de aislamiento térmico que tiende a retener la humedad que debería haberse evaporado. Esto incrementa la humedad interna, el moho y la putrefacción.

El vapor húmedo del interior se produce también al cocinar, lavar o secar ropa. Hay nuevos productos, como el yeso de arcilla, que tienen propiedades higroscópicas, lo que significa que pueden absorber y eliminar la humedad interior, lo que proporciona unas condiciones de vida más saludables para sus ocupantes.

Para desarrollar un nuevo sistema de aislamiento transpirable sería de gran ayuda contar con un mayor seguimiento y orientación, además del estudio del comportamiento de los habitantes y del mantenimiento de una adecuada ventilación en los edificios históricos rehabilitados. También es necesario conocer otros ejemplos de proyectos que hayan funcionado con información sobre las incidencias en el proceso de construcción, el rendimiento, los costes y la vida útil.

Es necesario un cambio urgente en la política del actual gobierno británico para la adaptación de los sistemas de aislamiento térmico en edificios construidos de manera tradicional, que suponen el $25 \%$ de las edificaciones del Reino Unido.

Los planes de subvenciones gubernamentales, como el "Pacto verde" (acuerdo del Gobierno británico para el 

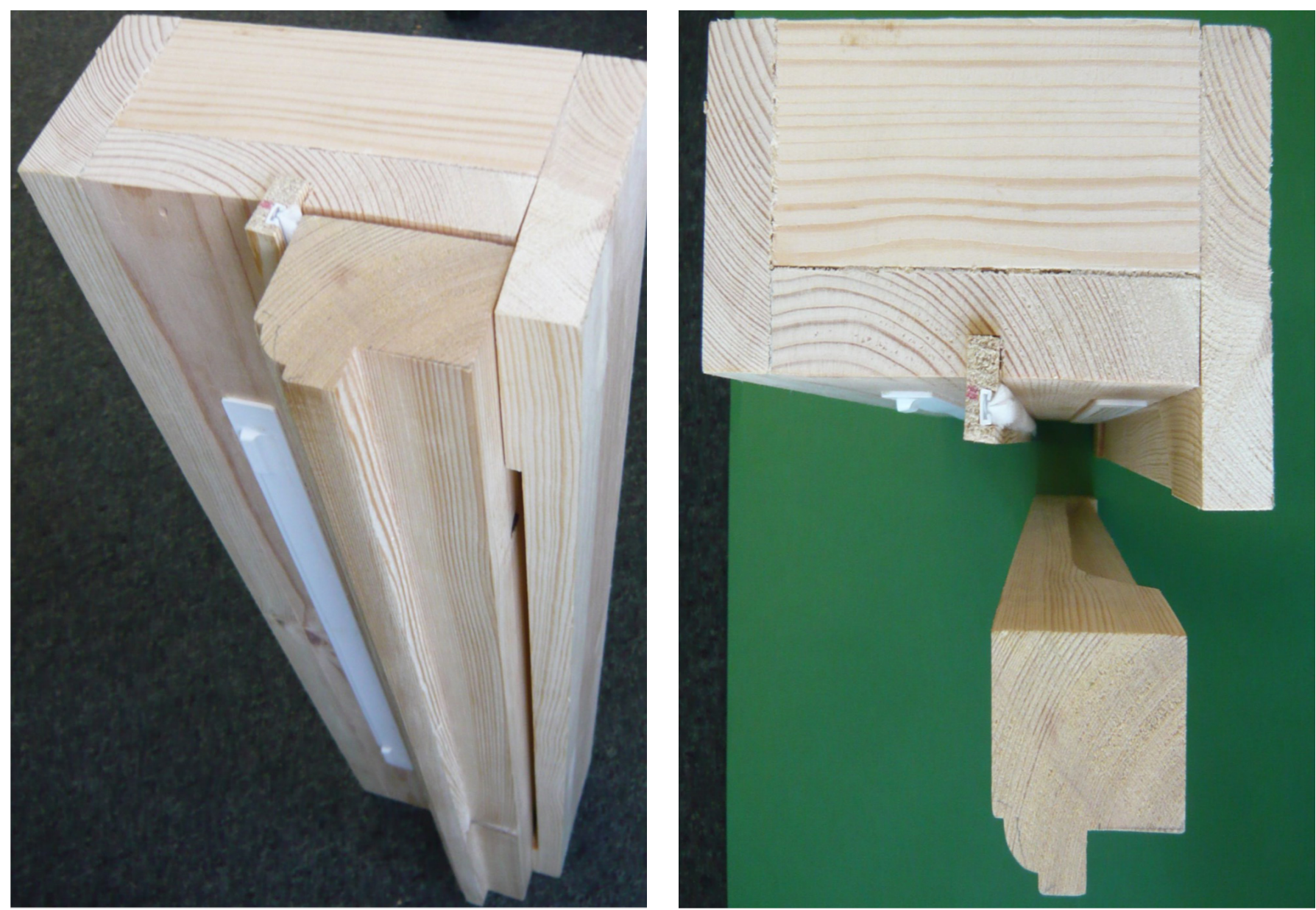

Detalle de un sistema de ventilación controlada para ventanas tradicionales tipo "guillotina" financiado por Camborne, Roskear, Tuckingmiill THI. Una ranura apenas visible se corta por la parte inferior de la caja delantera de la ventana para permitir la entrada de aire dosificada. Este rasgo está incorporado en el diseño sin dañar el conjunto y es resultado de la petición de muchos vecinos cuyas casas estaban próximas a vías urbanas con mucho tráfico que no solían abrir las ventanas | fotos Andrew Richards

ahorro energético), tienen intenciones positivas como la reducción del consumo de combustible y las emisiones de carbono y pueden contribuir a los objetivos del gobierno si se aplican de la manera apropiada. No obstante, estos planes no tienen en cuenta las diferencias entre las construcciones modernas y tradicionales. Esto probablemente resultará caro a largo plazo tanto en términos económicos como en emisiones de carbono, ya que será necesario realizar obras de reparación a cargo de estos planes ${ }^{1}$.

Los métodos de evaluación de la pérdida de calor que se utilizan para las construcciones antiguas (SAP y RdSAP) también pueden sobrevalorar sustancialmente la cantidad de aislamiento necesaria para mejorar los edificios tradicionales.

A nivel local, proyectos como la iniciativa para la protección del patrimonio de los centros históricos (Townscape Heritage Initiative), financiada por el Heritage Lottery Fund $^{2}$, ofrecen oportunidades de financiación para iniciativas de ahorro energético y de capacitación, que involucran a los profesionales locales del patrimonio, a las empresas constructoras, a los agentes locales y a los estudiantes universitarios. 
a debate La eficiencia energética y la edificación histórica | coordinan Mónica López Sánchez, Ana Yáñez Vega

La iniciativa para la protección del patrimonio de Camborne, Roskear y Tuckingmill, por ejemplo, ha financiado métodos para la rehabilitación respetuosa de edificios tradicionales y ha implicado a alumnos de universidades de la zona para controlar el ruido y el rendimiento térmico. También se han dado oportunidades de formación en técnicas tradicionales a los estudiantes de construcción, en proyectos reales financiados por el programa. Asimismo, se han alentado las reparaciones de los elementos tradicionales, lo que permite que los edificios se rehabiliten sin reemplazar o esconder los detalles originales.

Los resultados del seguimiento sirven para retroalimentar una guía web ${ }^{3}$ que se consulta al principio del proceso de planificación y antes de realizar la solicitud de "control de edificaciones", de manera que influyen en los nuevos proyectos de rehabilitación de edificios históricos.

La guía incluye los costes, actualizados con regularidad, y detalles sobre la vida útil de los productos, ejemplos de buenas prácticas en la zona y enlaces web de interés para profundizar en el tema. Actualmente se está avanzando en el control de la calidad del aire interior, para evaluar las consecuencias sobre la salud del uso de aislamiento transpirable y de la ventilación de los edificios históricos que se encuentran frente a carreteras muy transitadas.

Las ampliaciones tanto de los edificios históricos como de los nuevos que se encuentran en centros históricos podrían construirse con materiales más sostenibles e incorporar energías renovables. La remodelación de los edificios históricos debería incluir la previsión para una futura ampliación, mediante espacios en el techo y la posibilidad del trabajo a domicilio.

Los voluntarios y los agentes locales podrían colaborar para realizar inventarios de "patrimonio en riesgo", de manera que se localizarían edificios históricos vacíos adecuados para su rehabilitación. Los centros históricos de muchas ciudades inglesas tienen pisos altos vacíos o infrautilizados, lo que ha tenido como consecuencia un deficiente mantenimiento de la estructura externa del edificio. Y siempre existen oportunidades para trabajar con los agentes locales y las autoridades municipales de urbanismo y vivienda para recuperar el uso de las viviendas vacías. Esta opción es claramente más sostenible que continuar construyendo nuevos edificios.

\section{NOTAS}

1. Información tomada del Institute of Historic Buildings (IHBC) comments on Green Deal Investigation and Survey 18th November 2013. 2. Townscape Heritage-Heritage Lottery Fund (http://www.hlf.org.uk/
looking-funding/our-grant-programmes/townscape-heritage).

3. 'Improving Energy Efficiency in Historic Cornish Buildings' es accesible desde la página de Camborne, Roskear, Tuckingmill Regeneration, Energy and Skills Townscape Heritage Initiative website: http:// www.cornwall.gov.uk/environment-and-planning/conservation/heritage-led-regeneration/camborne-roskear-tuckingmill-townscape-heritage-initiatives/ 